\title{
Endoscopic management of accidental portal vein puncture during endoscopic ultrasound-guided choledochoduodenostomy
}

A 65-year-old woman was admitted to our department with obstructive jaundice secondary to locally advanced unresectable pancreatic adenocarcinoma. Biliary cannulation attempt was unsuccessful during endoscopic retrograde cholangiopancreatography; therefore, biliary drainage with endoscopic ultrasound (EUS)-guided choledochoduodenostomy (CDS) was planned with palliative intent ( $\vee$ Video $\mathbf{1}$ ).

An upstream common bile duct (CBD) dilatation (14 mm) was visualized on EUS ( Fig.1). A 0.025-inch guidewire was preloaded into a lumen-apposing metal stent (LAMS) $(8 \times 8 \mathrm{~mm})$ mounted onto an electrocautery-enhanced delivery system (Hot-AXIOS; Boston Scientific Co., Marlborough, Massachusetts, USA). The cautery-enabled access catheter was advanced through the duodenal bulb wall into the CBD using the "hybrid freehand" insertion technique [1]; however, the portal vein was accidentally punctured. Despite this severe complication, the delivery system was carefully withdrawn upwards until the internal flange was able to be deployed into the CBD while the proximal flange was deployed into the duodenal bulb under EUS guidance ( $\mathbf{F i g} \cdot \mathbf{2}$ ). After the LAMS had been delivered, severe bleeding was observed through the stent. Using a sphincterotome passed through a gastroscope, wire-guided access through the LAMS to the CBD was achieved ( $\triangleright$ Fig. $\mathbf{3}$ ). Then, a 0.025-inch guidewire (VisiGlide; Olympus Medical Systems Corp., Tokyo, Japan) was advanced across the tumor and the papilla. Following successful biliary cannulation after EUS-guided biliary rendezvous, a fully covered self-expandable metal stent (WallFlex Biliary RX Stent; Boston Scientific Co.) $(10 \times 60 \mathrm{~mm})$ was placed into the CBD to seal the disruption of the portal vein wall ( $\triangleright$ Fig. 4 ).

The patient was discharged home after 72 hours without further adverse events,
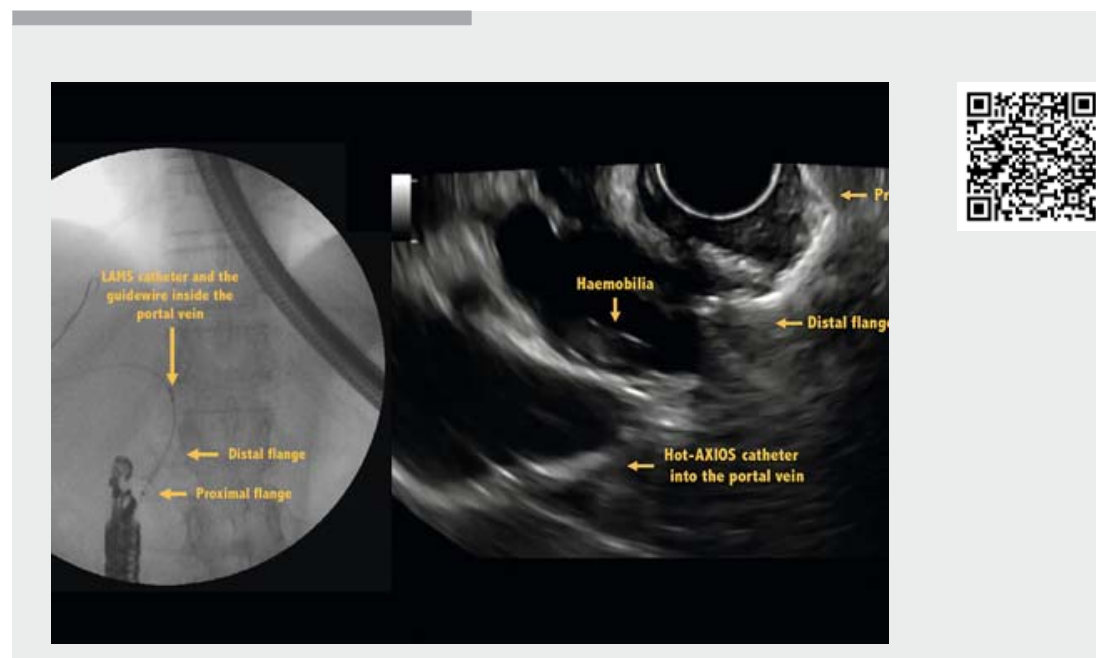

Video 1 Endoscopic management of accidental portal vein puncture during endoscopic ultrasound-guided choledochoduodenostomy.

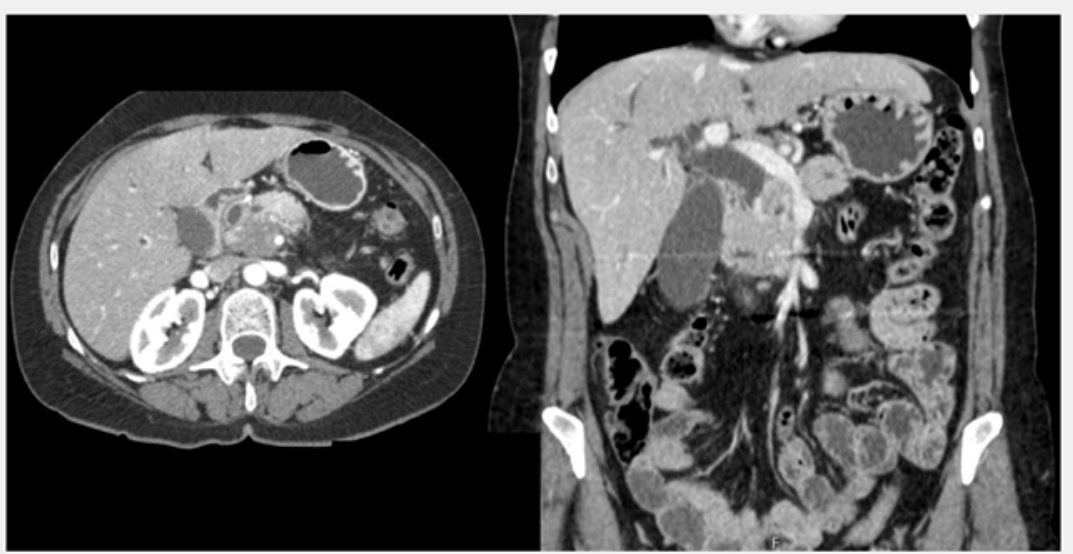

- Fig. 1 Pancreatic head adenocarcinoma ( $\mathrm{cT} 4 \mathrm{cN} 1 \mathrm{M} 0)$ and common bile duct dilatation.

and bilirubin levels returned to normal after 7 days.

Complications during EUS-CDS may occur [2-5], and the use of electrocauteryenhanced LAMS for this procedure is still in its infancy. Pre-existing guidewire access to the CBD before the advancement of a cautery-enabled stent delivery catheter may prevent complications.
Endoscopy_UCTN_Code_CPL_1AL_2AD

Competing interests

Dr. Aparicio is a consultant for Boston Scientific. 


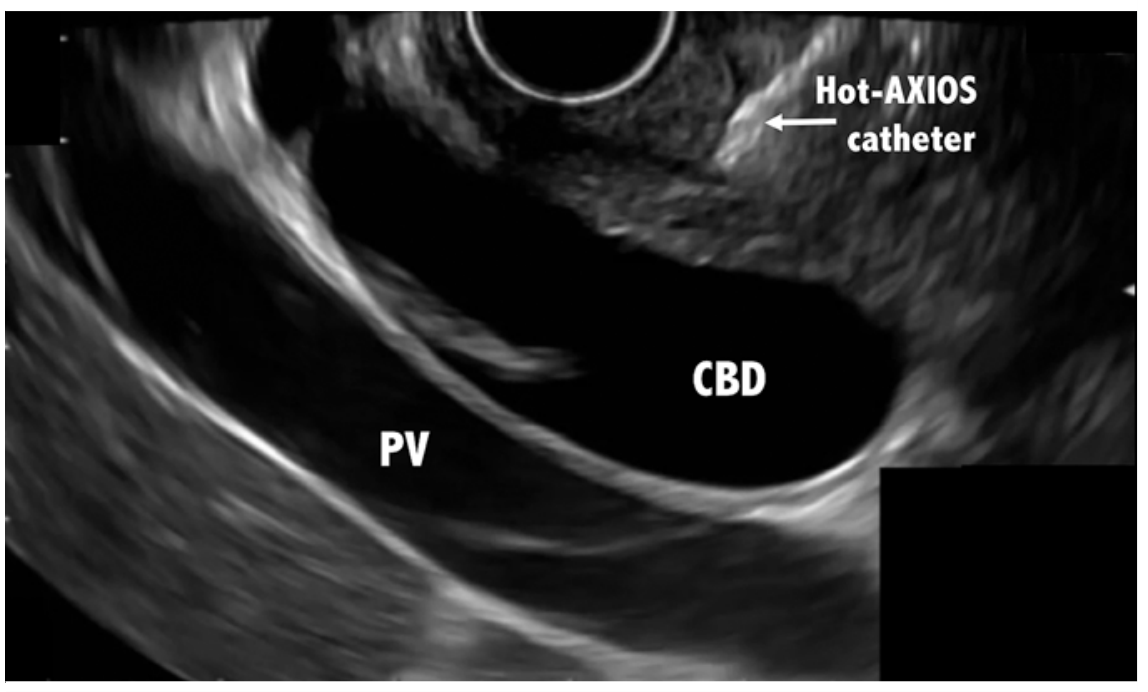

Fig. 2 An upstream dilatation of the common bile duct $(14 \mathrm{~mm})$ before the insertion of the Hot-AXIOS catheter (Boston Scientific Co., Marlborough, Massachusetts, USA). CBD, common bile duct; PV, portal vein.

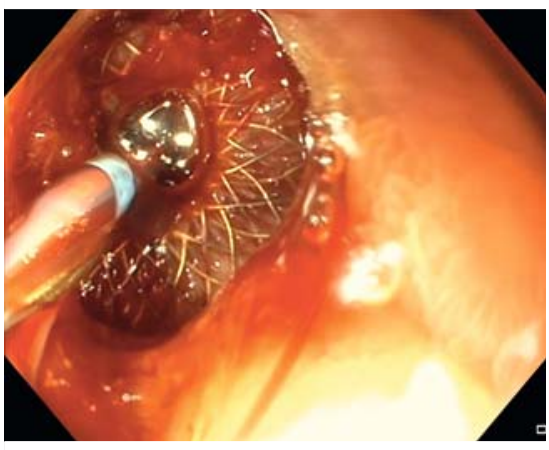

Fig. 3 Active bleeding trough the lumen-apposing metal stent after accidental portal vein puncture.

The authors

\section{Carolina Mangas-Sanjuan, Maryana Bozhychko, Juan Martinez, Luis Compañy, Francisco Ruiz, Juan Antonio Casellas, José Ramón Aparicio}

Endoscopy Unit, Hospital General Universitario de Alicante, Instituto de Investigación Sanitaria y Biomédica de Alicante, ISABIAL, Alicante, Spain

\section{References}

[1] Krishnan K, Raza A. EUS-guided choledochoduodenostomy with use of a lumenapposing metal stent: the freehand technique. VideoGIE 2018; 3: 49-50

[2] Dhir V, Itoi T, Khashab MA et al. Multicenter comparative evaluation of endoscopic placement of expandable metal stents for malignant distal common bile duct obstruction by ERCP or EUS-guided approach. Gastrointest Endosc 2015; 81: 913 - 923

[3] Khan MA, Akbar A, Baron TH et al. Endoscopic ultrasound-guided biliary drainage: a systematic review and meta-analysis. Dig Dis Sci 2016; 61: 684-703

[4] Tyberg A, Desai AP, Kumta NA et al. EUSguided biliary drainage after failed ERCP: a novel algorithm individualized based on patient anatomy. Gastrointest Endosc 2016; 84: $941-946$

[5] Kunda R, Pérez-Miranda M, Will U et al. EUS-guided choledochoduodenostomy for malignant distal biliary obstruction using a lumen-apposing fully covered metal stent after failed ERCP. Surg Endosc 2016; 30: $5002-5008$

\section{Bibliography}

DOI https://doi.org/10.1055/a-0991-7763

Published online: 9.9.2019

Endoscopy 2020; 52: E47-E48

(c) Georg Thieme Verlag KG

Stuttgart · New York

ISSN 0013-726X

Fig. 4 View of the self-expandable metal stent (SEMS) $(10 \times 60 \mathrm{~mm})$ delivered to seal the iatrogenic portal vein injury.

Corresponding author

\section{José Ramón Aparicio, MD}

Endoscopy Unit, Hospital General

Universitario de Alicante, C/Pintor Baeza 12, 03010 Alicante, Spain

Fax: +34-965-933468

japariciot@gmail.com

\section{ENDOSCOPY E-VIDEOS}

https://eref.thieme.de/e-videos

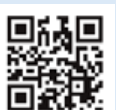

Endoscopy E-Videos is a free access online section, reporting on interesting cases and new

techniques in gastroenterological endoscopy. All papers include a high quality video and all contributions are freely accessible online.

This section has its own submission website at

https://mc.manuscriptcentral.com/e-videos 